\title{
Anti-echinococcal effect of verapamil involving the regulation of the calcium/ calmodulin-dependent protein kinase II response in vitro and in a murine infection model
}

Hai-Jun Gao ${ }^{1,2,3}$, Xu-Dong Sun ${ }^{1}$, Yan-Ping Luo ${ }^{1}$, Hua-Sheng Pang ${ }^{4}$, Xing-Ming Ma ${ }^{1}$, Ting Zhang ${ }^{2,4^{*}}$, Tao Jing ${ }^{1 *}$, Wei $\mathrm{Hu}^{2}, \mathrm{Yu}-J u a n \mathrm{Shen}^{2}$ and Jian-Ping Cao ${ }^{2}$

\begin{abstract}
Background: Echinococcosis, which is caused by the larvae of cestodes of the genus Echinococcus, is a parasitic zoonosis that poses a serious threat to the health of humans and animals globally. Albendazole is the drug of choice for the treatment of echinococcosis, but it is difficult to meet clinical goals with this chemotherapy due to its low cure rate and associated side effects after its long-term use. Hence, novel anti-parasitic targets and effective treatment alternatives are urgently needed. A previous study showed that verapamil (Vepm) can suppress the growth of Echinococcus granulosus larvae; however, the mechanism of this effect remains unclear. The aim of the present study was to gain insight into the anti-echinococcal effect of Vepm on Echinococcus with a particular focus on the regulatory effect of Vepm on calcium/calmodulin-dependent protein kinase II (Ca ${ }^{2+} / \mathrm{CaM}-\mathrm{CaMKII)}$ in infected mice.
\end{abstract}

Methods: The anti-echinococcal effects of Vepm on Echinococcus granulosus protoscoleces (PSC) in vitro and Echinococcus multilocularis metacestodes in infected mice were assessed. The morphological alterations in Echinococcus spp. induced by Vepm were observed by scanning electron microscopy (SEM), and the changes in calcium content in both the parasite and mouse serum and liver were measured by SEM-energy dispersive spectrometry, inductively coupled plasma mass spectrometry and alizarin red staining. Additionally, the changes in the protein and mRNA levels of CaM and CaMKII in infected mice, and in the mRNA levels of CaMKII in E. granulosus PSC, were evaluated after treatment with Vepm by immunohistochemistry and/or real-time quantitative polymerase chain reaction.

Results: In vitro, E. granulosus PSC could be killed by Vepm at a concentration of $0.5 \mu \mathrm{g} / \mathrm{ml}$ or higher within 8 days. Under these conditions, the ultrastructure of PSC was damaged, and this damage was accompanied by obvious calcium loss and downregulation of CaMKII mRNA expression. In vivo, the weight and the calcium content of $E$.

\footnotetext{
*Correspondence: zhangting@nipd.chinacdc.cn; landa021001@126.com

1 School of Basic Medical Sciences, Lanzhou University, Lanzhou 730000,

Gansu Province, People's Republic of China

${ }^{2}$ National Institute of Parasitic Diseases, Chinese Center for Disease

Control and Prevention, WHO Collaborating Center for Tropical Diseases,

National Center for International Research on Tropical Diseases, Key

Laboratory of Parasite and Vector Biology of the Chinese Ministry

of Health, Shanghai 200025, People's Republic of China

Full list of author information is available at the end of the article
}

c) The Author(s) 2021. This article is licensed under a Creative Commons Attribution 4.0 International License, which permits use, sharing, adaptation, distribution and reproduction in any medium or format, as long as you give appropriate credit to the original author(s) and the source, provide a link to the Creative Commons licence, and indicate if changes were made. The images or other third party material in this article are included in the article's Creative Commons licence, unless indicated otherwise in a credit line to the material. If material is not included in the article's Creative Commons licence and your intended use is not permitted by statutory regulation or exceeds the permitted use, you will need to obtain permission directly from the copyright holder. To view a copy of this licence, visit http://creativeco mmons.org/licenses/by/4.0/. The Creative Commons Public Domain Dedication waiver (http://creativecommons.org/publicdomain/ zero/1.0/) applies to the data made available in this article, unless otherwise stated in a credit line to the data. 
multilocularis metacestodes from mice were reduced after treatment with $40 \mathrm{mg} / \mathrm{kg}$ Vepm, and an elevation of the calcium content in the sera and livers of infected mice was observed. In addition, downregulation of CaM and CaMKII protein and mRNA expression in the livers of mice infected with E. multilocularis metacestodes was found after treatment with Vepm.

Conclusions: Vepm exerted a parasiticidal effect against Echinococcus both in vitro and in vivo through downregulating the expression of $\mathrm{Ca}^{2+} / \mathrm{CaM}$-CaMKII, which was over-activated by parasitic infection. The results suggest that $\mathrm{Ca}^{2+} / \mathrm{CaM}-\mathrm{CaMKII}$ may be a novel drug target, and that Vepm is a potential anti-echinococcal drug for the future control of echinococcosis.

Keywords: Verapamil, Echinococcus, Calmodulin, Calcium-calmodulin-dependent protein kinases

\section{Background}

Echinococcosis is a serious but neglected helminthic zoonosis caused by members of the genus Echinococcus, and mainly by Echinococcus granulosus, which causes cystic echinococcosis (CE), and Echinococcus multilocularis, which causes alveolar echinococcosis (AE) [1]. CE occurs globally, and AE occurs in the northern hemisphere and imposes a heavy disease burden [2]. According to data from central Asia, at least 270 million people are exposed to Echinococcus, and the prevalence of the disease in some areas of Tibet in western China ranges from 0.8 to $11.9 \%$ [3]. Higher pathogenicity and case fatality rate are notably associated with $\mathrm{AE}$ due to its tumor-like growth [3]. The clinical treatment strategies for echinococcosis include surgery and chemotherapy. Albendazole (ABZ), a benzimidazole derivative, is the main chemotherapeutic drug used for the treatment of human echinococcosis [4]; it exerts an anti-parasitic effect by disrupting microtubule polymerization and biochemical processes, such as glucose and energy metabolism, in the parasite [5]. However, ABZ exerts parasitostatic rather than parasiticidal effects [6], has poor gastrointestinal absorption and is associated with severe side effects $[7,8]$. Hence, new drugs for the treatment of this parasitosis have been investigated, such as traditional Chinese medicines derived from botanical extracts [9], antineoplastic chemotherapeutics [7, 10], and immunosuppressants [11, 12]. However, only a few of these agents, such as mefloquine and amphotericin B alone or in combination with nitazoxanide, have been used as auxiliary treatments for human echinococcosis [6]. Therefore, investigation of novel anti-Echinococcus drugs and drug targets is urgently needed.

$\mathrm{Ca}^{2+}$, a pivotal second messenger, controls physiological processes in cells, such as proliferation, differentiation and migration [13]. The complex consisting of $\mathrm{Ca}^{2+}$ and calmodulin (CaM) can specifically bind to CaM-dependent protein kinases (CaMKs; including CaMKI, CaMKII, CaMKIII and CaMKIV) to activate the $\mathrm{Ca}^{2+} / \mathrm{CaM}$-CaMK cascade, which can promote signal transduction in cells [14]. Previous studies in tumors have shown that the $\mathrm{Ca}^{2+} / \mathrm{CaM}$-CaMK cascade controls tumorigenesis and tumor progression [13, 15, 16]. Furthermore, the $\mathrm{Ca}^{2+} / \mathrm{CaM}-\mathrm{CaMK}$ cascade has been suggested to be closely related to the pathogenesis of many hepatic parasites. For example, in Schistosoma mansoni, the IQ motif of SmCav1B, which is a voltagegated calcium channel, can interact with two CaMs, SmCaM1 and SmCaM2, to promote growth [17], and RNA interference silencing of a calcium-regulated protein affects the morphology and vitality of Schistosoma japonicum [18]. Two voltage-gated calcium channel $\beta$-subunits, $\mathrm{CsCa}_{\mathrm{v}} \beta 1$ and $\mathrm{CsCa}_{\mathrm{v}} \beta 2$, boost the parasiticidal effect of praziquantel on Clonorchis sinensis [19], and $F h C a M$ dyshomeostasis can clearly block growth and motility in Fasciola hepatica [20]. Therefore, $\mathrm{Ca}^{2+} /$ CaM-CaMKs are potential therapeutic targets in cancers and parasitosis, and calcium channel inhibitors, such as verapamil (Vepm) and praziquantel, have been confirmed to have anti-tumorigenic and anti-parasitic effects [13, 15, 21, 22]. Furthermore, Vepm has been shown to alleviate atrial fibrillation in rats by downregulating the expression of over-activated Cav1.2-CaMCaMKII [23]. In E. granulosus protoscoleces (PSC), the presence of calcareous corpuscles indicate that calcium sources are required for hydatid cyst development [24], and the calcium level in hydatid cysts has been shown to be higher than that in the serum or plasma of the host [25]. Previous studies have confirmed that Vepm suppresses the growth of E. granulosus larvae $[26,27]$; however, it is unclear whether this compound has similar anti-parasitic effects on E. multilocularis, which has a tumor-like larval stage, and is more harmful to humans. The mechanism of action of Vepm against Echinococcus has never been investigated, and it is unclear whether the inhibitory effects of Vepm on E. granulosus are mediated by the regulation of $\mathrm{Ca}^{2+}$ / CaM-CaMKII. Hence, this study aimed to investigate the efficacy and mechanism of action of Vepm against Echinococcus. 


\section{Methods}

\section{Biochemical reagents}

Vepm (V111249), ABZ (A131023), albendazole sulfoxide (ABZ-SO; 35395) and pentobarbital sodium were purchased from Sigma (MI) and Aladdin (Shanghai, China). Antibodies and polymerase chain reaction (PCR) primers were purchased from Abcam (Cambridge, MA) and Beijing Genomics Institute (Beijing). Enzyme-linked immunosorbent assay (ELISA) kits for CaM and CaMKII were purchased from CUSABIO (Wuhan, China). All culture reagents were purchased from Gibco (Wisent, Canada). Extraction kits for total RNA and PCR kits were purchased from Takara (Tokyo).

\section{Separation and culture of E. granulosus PSC in vitro}

E. granulosus PSC were obtained from the livers of naturally infected sheep from the slaughterhouse of Xining City, Qinghai Province, China. The PSC were rinsed with phosphate buffered saline (PBS), resuspended in Dulbecco's modified Eagle's medium containing 1\% penicillin-streptomycin, and then incubated in 24-well culture plates (100 PSC/well) at $37{ }^{\circ} \mathrm{C}, 5 \% \mathrm{CO}_{2}$. Morphological alterations in the PSC were observed under an inverted microscopy (BX43; Olympus, Japan), and the survival rate of PSC was recorded daily.

\section{Mouse infection with E. multilocularis}

Kunming mice 6-8 weeks of age were purchased from the Laboratory Animal Center of Lanzhou University and housed in a high-efficiency particulate air-filtered and temperature-controlled environment under a light/ dark cycle at $22-25{ }^{\circ} \mathrm{C}$. The mice were fed a rodent diet (Beijing Keao; Beijing) ad libitum under specific-pathogen-free laboratory conditions. E. multilocularis PSC were aseptically isolated from anaesthetized $E$. multilocularis-infected gerbils in our laboratory as described previously [28] to establish a murine infection model by in situ surgical intrahepatic implantation. Healthy mice were infected with E. multilocularis PSC (1500 PSC/ mouse) $(n=15)$ under specific-pathogen-free laboratory conditions, or were subjected to a sham procedure and used as the uninfected group $(n=5)$; both groups were housed under the same conditions.

\section{Drug treatment in vitro}

The experimental groups were divided into (i) the vehicle group, which was treated with $0.1 \%$ dimethylsulfoxide (DMSO) $(n=3)$; (ii) the ABZ-SO group, which was treated with 40 and $20 \mu \mathrm{g} / \mathrm{ml} \mathrm{ABZ-SO}$ dissolved in $0.1 \%$ DMSO $(n=3)$; and (iii) the Vepm groups, which were treated with $100,80,40,20,10,5,2,1$ or $0.5 \mu \mathrm{g} /$ $\mathrm{ml}$ Vepm $(n=3)$. After drug treatment, E. granulosus PSC were stained with $0.4 \%$ trypan blue for $10 \mathrm{~min}$ to observe morphological changes. In addition, E. granulosus PSC were fixed with $4 \%$ glutaraldehyde, rinsed with PBS $(1 \times)$, and stained with $2 \%$ osmium tetroxide for $2 \mathrm{~h}$ and $1 \%$ uranyl acetate for $30 \mathrm{~min}$. Subsequently, these specimens were dehydrated in increasing concentrations of ethanol, air-dried and coated with gold as described previously [28]. Finally, the microstructure of the PSC was observed by scanning electron microscopy (SEM) (JSM-5600LV; JEOL, Japan).

\section{Drug treatment in vivo}

Three months after infection with E. multilocularis PSC, the infected mice were divided into the following groups for oral drug administration: (i) infected mice treated daily with honey/PBS $(1: 1 \mathrm{v} / \mathrm{v})(n=5)$; (ii) infected mice treated daily with $40 \mathrm{mg} / \mathrm{kg} \mathrm{ABZ}$ in honey/PBS $(1: 1 \mathrm{v} / \mathrm{v})(n=5)$; (iii) infected mice treated daily with $40 \mathrm{mg} / \mathrm{kg}$ Vepm in honey/PBS $(1: 1 \mathrm{v} / \mathrm{v})(n$ $=5$ ). (iv) The uninfected mice were treated daily with honey/PBS $(1: 1 \mathrm{v} / \mathrm{v})(n=5)$. After 4 months of treatment, E. multilocularis cysts, sera and livers were harvested from the mice to measure the calcium content and CaM and CaMKII protein and mRNA expression.

\section{Calcium content analysis by inductively coupled plasma mass spectrometry, SEM-energy dispersive spectrometry and alizarin red staining}

i. For inductively coupled plasma mass spectrometry (ICP-MS) analysis, equal amounts of tissue or serum/culture supernatant samples were prepared for calcium analysis. Tissue digestion was performed with a microwave digestion system using UltraClave (Milestone; Sorisole, Italy), and sample analysis was performed as described previously [29].

ii. For SEM-energy dispersive X-ray spectroscopy (SEM-EDS) analysis, changes in the calcium content in E. granulosus PSC and in the germinal layer cells of $E$. multilocularis metacestodes were observed after treatment with Vepm by a LEO Gemini field emission gun scanning electron microscope (JEOL, Japan) as described previously [30].

iii. For alizarin red staining, E. multilocularis metacestodes and mouse livers were fixed with $4 \%$ paraformaldehyde for 2 weeks, and then stained with alizarin red to detect calcification, as described previously [31]. The percentage of positively stained calcium deposits in the images was calculated by using ImageJ software (National Institutes of Health, Bethesda, MD). 
Analysis of CaM and CaMKII protein expression analysis by immunohistochemistry-paraffin and ELISA

i. For immunohistochemistry-paraffin (IHC-P), 4- $\mu \mathrm{m}$-thick sections of $E$. multilocularis metacestodes and mouse livers were processed to evaluate the expression of CaM or CaMKII, as described previously [32, 33]; immunostaining was performed using rabbit anti-CaM/CaMKII antibodies (Bioss; Beijing) at 1:300/1:200 dilution and secondary antibodies (goat anti-rabbit immunoglobulin G; Bioss) at 1:800 dilution. Finally, the slides were imaged under a fluorescence microscopy (Olympus, Japan). Semiquantitative analysis was performed by using ImageJ software.

ii. For ELISA, PBS ( $\mathrm{pH}=7.2)$ containing phenylmethylsulfonyl fluoride $(10 \mathrm{mmol} / \mathrm{l})$ was added to serum and tissue samples, which were then rapidly homogenized and centrifuged at $1000 \times g$ for 10 min to measure the protein concentrations of $\mathrm{CaM}$ and CaMKII according to the ELISA kit protocols.

\section{Analysis of CaM and CaMKII mRNA expression by real-time quantitative PCR}

The expression of CaM or/and CaMKII mRNA in E. granulosus PSC, mouse livers and E. multilocularis cysts was measured by real-time quantitative PCR (RT-qPCR), and $\beta$-actin mRNA was used as the internal standard. Nucleic acid was isolated from various tissues by using TRIzol reagent (Invitrogen, San Diego, CA), and reversetranscribed into cDNA; amplification of cDNA was performed by RT-qPCR following the Takara kit protocol (no. RR036A). The following primers were used: $E g$ CaMKII/Em-CaMKII (forward, 5'-TCGTTGTTCAAG TCGGTTCG- ${ }^{\prime}$; reverse, $5^{\prime}$-GGTGCTGAGAGACCC ACTAG-3'), Eg- $\beta$-actin/Em- $\beta$-actin (forward, 5'-AGA CATCAGGGAGTGATGGTT-3'; reverse, $5^{\prime}$-GAGGAC TGGATGCTCCTCAGG-3'); mouse CaMKII (forward, 5'-GGCCTGGACTTTCATCGATTCTA-3'; reverse, 5'-CATCAGGTGGATGTGAGGGTTC-3'), mouse CaM (forward, 5'-AAGCCGAGCTGCAGGATATGA3'; reverse, 5'-CAGTTCTGCCGCACTGATGTAA-3'), and mouse $\beta$-actin (forward, $5^{\prime}$-TTGTTACCAACTGGG ACG-3'; reverse, 5'-GGCATAGAGGTCTTTACGG-3').

\section{Statistical analysis}

The data are presented as the mean \pm SD. Statistical differences between the groups were assessed by $t$-test and paired comparisons. Statistical analysis was performed by SPSS version 22.0 (IBM, Chicago, IL) and GraphPad Prism version 7.0 (GraphPad Software, San Diego, CA). P $<0.05$ indicates significant differences.

\section{Results}

\section{Effect of Vepm on E. granulosus PSC in vitro}

The survival rate of E. granulosus PSC after treatment with various concentrations of $\operatorname{Vepm}(0.5,1,2,5,10,20$, 40, 80 or $100 \mu \mathrm{g} / \mathrm{ml}$ ) within 8 days is shown in Fig. 1a. The mortality of PSC upon exposure to $0.5-40 \mu \mathrm{g} / \mathrm{ml}$ Vepm was time dependent; all PSC were killed within 2 days by $40 \mu \mathrm{g} / \mathrm{ml} \mathrm{Vepm}$ or within 4 days by $20 \mu \mathrm{g} / \mathrm{ml}$ Vepm. However, ABZ-SO had killed only $13 \%$ of PSC on day 2 when administrated at a concentration of $40 \mu \mathrm{g} / \mathrm{ml}$ and $21 \%$ of PSC on day 4 when administrated at a concentration of $20 \mu \mathrm{g} / \mathrm{ml}$; $4 \%$ of PSC in the vehicle group were dead on day 2 , and $8 \%$ of PSC were dead on day 4 .

Under light microscopy, comparison with the natural morphology of PSC in the vehicle group indicated mild morphological alterations of PSC in the ABZ-SO $(20 \mu \mathrm{g} /$ $\mathrm{ml}$ ) group and substantial morphological alterations (i.e., disappearance of calcareous corpuscles) of PSC after exposure to $20 \mu \mathrm{g} / \mathrm{ml} \mathrm{Vepm} \mathrm{for} 4$ days (Fig. 1b, $a-c$ ). Additionally, PSC in the Vepm $(20 \mu \mathrm{g} / \mathrm{ml})$ group were stained with trypan blue on day 4, unlike the viable PSC in the ABZ-SO $(20 \mu \mathrm{g} / \mathrm{ml})$ and vehicle groups (Fig. 1b, $d-f)$. SEM showed that the ultrastructural changes that occurred in PSC exposed to Vepm $(20 \mu \mathrm{g} / \mathrm{ml})$ for 4 days were shedding of the tegument, disappearance of hooks and the presence of numerous blebs; however, PSC in the vehicle and ABZ-SO $(20 \mu \mathrm{g} / \mathrm{ml})$ groups remained intact (Fig. 1b, $g-i)$.

\section{Changes in the calcium content in E. granulosus PSC exposed to Vepm in vitro}

The calcium distribution in E. granulosus PSC treated with Vepm $(20 \mu \mathrm{g} / \mathrm{ml})$ for 4 days was heterogeneous and sparse compared with that in the vehicle group, as determined by SEM-EDS (Fig. 2a). Semiquantitative analysis showed that the calcium level in PSC decreased after treatment with Vepm (Fig. 2b). In addition, a clear dosedependent increase in the calcium content in the culture supernatant of the Vepm group compared with the vehicle group was observed (Fig. 2c).

\section{Effect of Vepm on E. multilocularis metacestodes in vivo}

E. multilocularis-infected mice were treated with Vepm (40 $\mathrm{mg} / \mathrm{kg})$ or $\mathrm{ABZ}(40 \mathrm{mg} / \mathrm{kg}$ ) for 4 months in vivo. The wet weights of $E$. multilocularis cysts isolated from the Vepm $(0.98 \pm 0.33 \mathrm{~g})$ and $\mathrm{ABZ}$ groups $(1.04 \pm 0.14$ g) were significantly lower than those from the infected group $(5.90 \pm 0.75 \mathrm{~g})(P=0.000$; Table 1$)$.

\section{Changes in the calcium concentration in $E$. multilocularis-infected mice after Vepm treatment} The calcium concentration in the sera of E. multilocularis-infected mice was $4.92 \pm 0.77 \mathrm{mg} / \mathrm{l}$, which represented a twofold decrease compared with that in the 


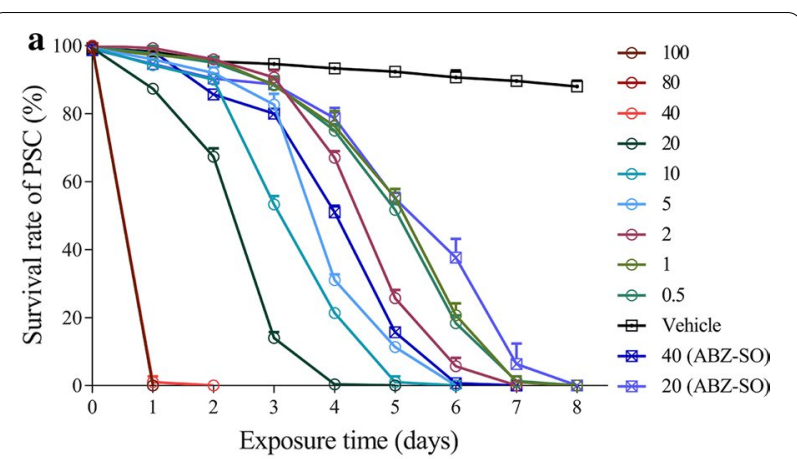

b

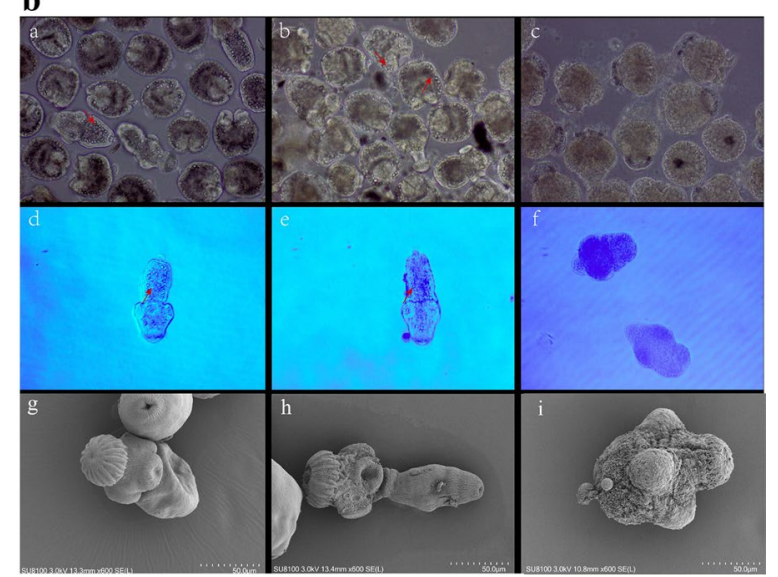

Fig. 1a, b The effect of verapamil (Vepm) against Echinococcus granulosus protoscoleces (PSC) in vitro. a E. granulosus PSC were exposed to Vepm at a concentration of $0.5-100 \mu \mathrm{g} / \mathrm{ml}$, albendazole sulfoxide (ABZ-SO) at a concentration of 40 or $20 \mu \mathrm{g} / \mathrm{ml}$, or $0.1 \%$ dimethylsulfoxide (the vehicle group) for 8 days. b The morphological changes and ultrastructural alterations in PSC exposed to various drugs for 4 days were detected by light microscopy and scanning electron microscopy (SEM). $a, d, g$ Typical morphology and structural integrity of PSC from the vehicle group. $b, e, h$ Mild morphological and structural alterations in the ABZ-SO $(20 \mu \mathrm{g} / \mathrm{ml})$ group. $c, f, j$ Substantial morphological and ultrastructural destruction of PSC exposed to Vepm $(20 \mu \mathrm{g} / \mathrm{ml})$, including disappearance of calcareous corpuscles and hooks, shedding of the tegument and the presence of numerous blebs. a-c Light microscopy without any staining ( $\times 200$ magnification); $d-f$ light microscopy with trypan blue staining (×200 magnification); g-i SEM (×600 magnification). Red arrowhead indicates an intact calcareous corpuscle

uninfected group $(9.89 \pm 1.92 \mathrm{mg} / \mathrm{l})$; treatment with Vepm for 4 months induced a recovery of the calcium concentration to $6.39 \pm 0.79 \mathrm{mg} / \mathrm{l}$ (Table 2). Similarly, the level of calcium in the livers of mice decreased, from $296.72 \pm 9.43 \mathrm{mg} / \mathrm{l}$ to $172.72 \pm 16.63 \mathrm{mg} / \mathrm{l}$, due to $E$. multilocularis metacestode infection. Interestingly, the calcium content in the livers increased to $226.78 \pm 43.93$ $\mathrm{mg} / \mathrm{l}$ after treatment with Vepm $(P=0.009)$. The ICPMS assay showed that the calcium level in E. multilocularis cysts isolated from the infected group was 3182.28 $\pm 190.77 \mathrm{mg} / \mathrm{l}$; the level decreased to $3013.98 \pm 115.80$ $\mathrm{mg} / \mathrm{l}$ after treatment with Vepm for 4 months $(P=0.13)$. Additionally, changes in the calcium level in E. multilocularis cysts were evaluated by SEM-EDS (Fig. 3a), which showed that the percentage of calcium by weight in $E$. multilocularis cysts rapidly decreased from $14.28 \%$ to $8.66 \%$ after treatment with Vepm; these differences were statistically significant $(P=0.000)$ (Fig. 3b). The results of alizarin red staining showed that calcium deposition around the portal area of the liver in infected mice was significantly increased compared with that in the uninfected group (Fig. 4). The decrease in calcium content in the infected livers was not reversed by treatment with Vepm. The calcium content in E. multilocularis cysts was not obviously reduced $(P>0.05)$; however, a reduction in the number of PSC was observed.

\section{Analysis of CaM and CaMKII protein levels in $E$. multilocularis-infected mice treated with Vepm}

IHC-P staining revealed high expression of CaM in the livers of infected mice compared with those of uninfected mice (Fig. 5a); however, pathological progression was inhibited by Vepm, and the differences were statistically significant $(P<0.05)$. Furthermore, ELISA showed that the CaM protein concentration in mouse serum and liver increased significantly from $13.81 \pm 1.65$ to $22.25 \pm$ $5.55 \mu \mathrm{g} / \mathrm{ml}$ and from $3.42 \pm 0.27$ to $6.06 \pm 1.83 \mu \mathrm{g} / \mathrm{ml}$, respectively, after $E$. multilocularis infection; however, after treatment with Vepm, CaM protein expression was clearly inhibited in the serum $(8.13 \pm 1.26 \mu \mathrm{g} / \mathrm{ml})$ and liver $(1.60 \pm 0.68 \mu \mathrm{g} / \mathrm{ml}$ ) but not in the cysts (from $2.36 \pm$ 0.87 to $1.68 \pm 0.10 \mu \mathrm{g} / \mathrm{ml}$ ) (Table 3).

Similar to that of CaM, the IHC-P assay indicated that the overexpression of CaMKII in the livers and cysts in $E$. multilocularis-infected mice was significantly suppressed by Vepm treatment (Fig. 5b). Additionally, an increase in CaMKII content in mouse serum $(22.87 \pm 4.23 \mathrm{ng} /$ $\mathrm{ml})$ and liver $(4.25 \pm 1.84 \mathrm{ng} / \mathrm{ml})$ was observed after $E$. multilocularis infection; the CaMKII content decreased to $5.13 \pm 1.74 \mathrm{ng} / \mathrm{ml}$ and $1.97 \pm 0.56 \mathrm{ng} / \mathrm{ml}$, respectively, after Vepm treatment. However, only a mild decrease in CaMKII content in the cysts (from $2.65 \pm 1.24$ to $1.79 \pm$ $0.36 \mathrm{ng} / \mathrm{ml})$ was observed after Vepm treatment $(P>0.05$; Table 3).

\section{Analysis of CaM and CaMKII mRNA expression in the parasite and in E. multilocularis-infected mice after treatment with Vepm}

The changes in $\mathrm{Ca}^{2+} / \mathrm{CaM}-\mathrm{CaMKII}$ expression in parasite-infected mice after treatment with Vepm were evaluated based on the changes in CaM and/or CaMKII mRNA expression in the mouse liver and in Echinococcus, as measured by using RT-qPCR. CaM and CaMKII mRNA expression in the mouse liver increased fourfold 

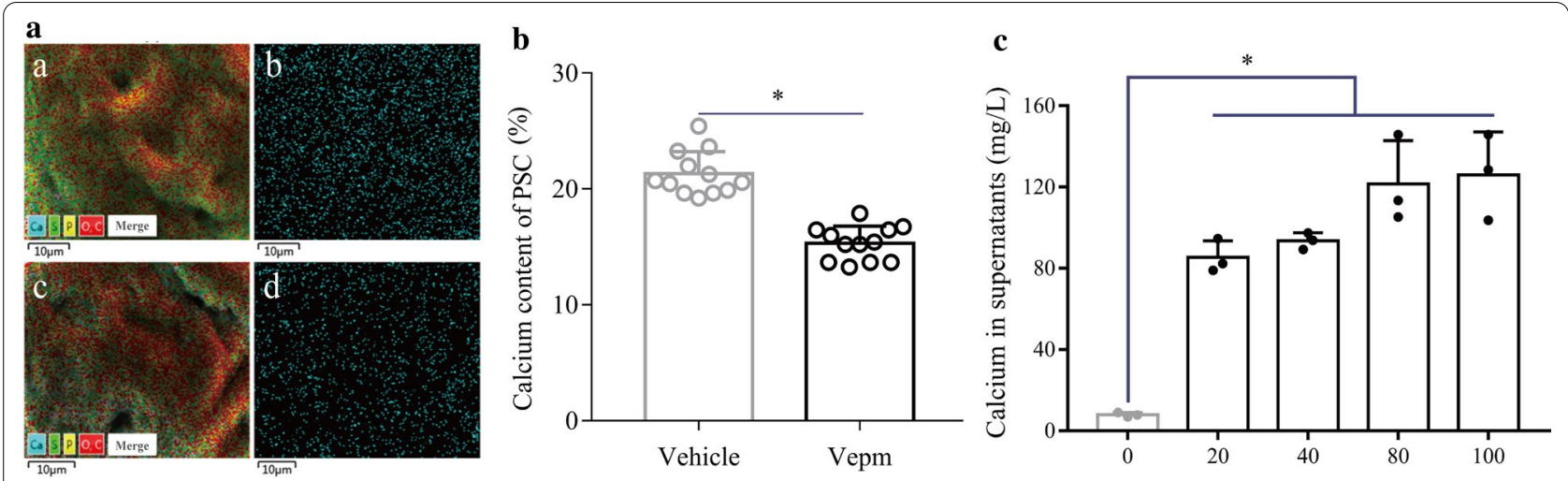

Fig. 2a-c Changes in the calcium content in E. granulosus PSC after treatment with $20 \mu \mathrm{g} / \mathrm{ml}$ Vepm for 4 days in vitro. a Calcium distribution in E. granulosus PSC, as assayed by SEM-energy dispersive X-ray spectrometry (SEM-EDS). Merged image of multi-element $(a, c)$ and calcium $(b, d)$ distributions in PSC in the vehicle $(a, b)$ and the Vepm groups $(c, d)$. b Percentage of calcium content in E. granulosus PSC, as measured by SEM-EDS. c Calcium content in the culture supernatants of E. granulosus PSC exposed to Vepm $(0,20,40,80,100 \mu \mathrm{g} / \mathrm{ml})$ as measured by inductively coupled plasma mass spectrometry. For other abbreviations, see Fig. 1

Table 1 Changes in the wet weight of Echinococcus multilocularis metacestodes in mice after treatment with verapamil (Vepm) for 4 months

\begin{tabular}{llll}
\hline Group & No. of mice & Dose & $\begin{array}{l}\text { Cyst weight } \\
\text { (g) (mean } \pm \\
\text { SD) }\end{array}$ \\
\hline Infected & 5 & NA & $5.90 \pm 0.75$ \\
ABZ & 5 & $40 \mathrm{mg} / \mathrm{kg}$ per day & $1.04 \pm 0.14^{*}$ \\
Vepm & 5 & $40 \mathrm{mg} / \mathrm{kg}$ per day & $0.98 \pm 0.33^{*}$ \\
\hline
\end{tabular}

ABZ Albendazole, $N A$ not available

${ }^{*} P<0.05$ (statistical analysis was performed by comparison with the infected group)

Table 2 Inductively coupled plasma mass spectrometry analysis of the calcium content in the sera, livers and cysts of $E$. multilocularis-infected mice after treatment with Vepm for 4 months

\begin{tabular}{lrrr}
\hline Sample & \multicolumn{3}{l}{ Calcium concentration $(\mathrm{mg} / \mathrm{l})$} \\
\cline { 2 - 4 } & Uninfected group & Infected group $^{\text {a }}$ & Vepm group $^{\mathrm{b}}$ \\
\hline Serum & $9.89 \pm 1.92$ & $4.92 \pm 0.77^{*}$ & $6.39 \pm 0.79$ \\
Liver & $296.72 \pm 9.43$ & $172.72 \pm 16.63^{*}$ & $226.78 \pm 43.93^{*}$ \\
Cyst & NA & $3182.28 \pm 190.77$ & $3013.98 \pm 115.80$ \\
\hline${ }^{*} P<0.05$ & & \\
a Infected group vs. the uninfected group \\
b Vepm group vs. the infected group
\end{tabular}

and sixfold, respectively, after infection with Echinococcus (Fig. 6a, b). Overexpression of CaM and CaMKII mRNA in the liver was significantly suppressed by Vepm $(P=0.000)$. After treatment with Vepm, CaMKII mRNA expression was clearly downregulated, while CaM mRNA expression was mildly reduced $(P>0.05)$. Furthermore,
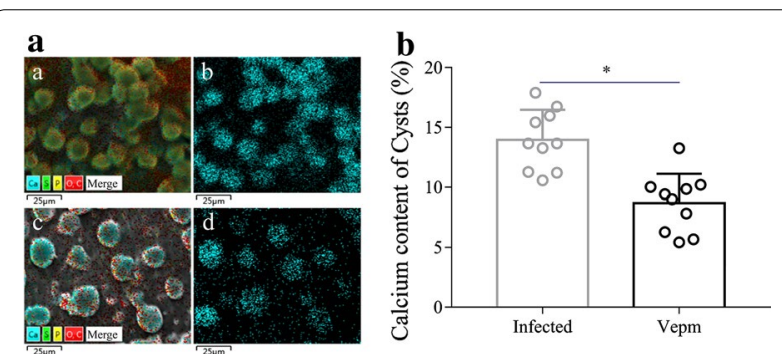

Fig. 3a, b Changes in the calcium content of $E$.

multilocularis-infected mice after treatment with $40 \mathrm{mg} / \mathrm{kg}$ Vepm for 4 months, as measured by SEM-EDS. a Calcium distribution in the germinal layer of E. multilocularis cysts. Merged image of multi-element $(a, c)$ and calcium $(b, d)$ distributions in the germinal layer of the infected $(a, b)$ and Vepm groups $(c, d)$. b Percentage of calcium content in the germinal layer of E. multilocularis metacestodes in mice after treatment with Vepm. For abbreviations, see Figs. 1 and 2
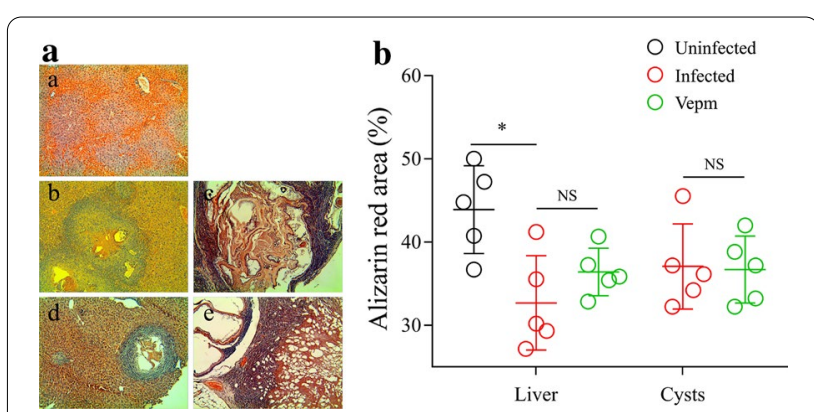

Fig. 4a, b Changes in the calcium content in the liver and $E$. multilocularis cysts in mice after treatment with $40 \mathrm{mg} / \mathrm{kg}$ Vepm for 4 months, as measured by alizarin red staining. a Calcium distribution in the liver $(a, b, d)$ and E. multilocularis cysts $(c, e)$ from uninfected $(a)$, infected $(b, c)$ and Vepm-treated $(d, e)$ mice ( $\times 200$ magnification). b Semiquantitative analysis of calcium content. NS Not significant 

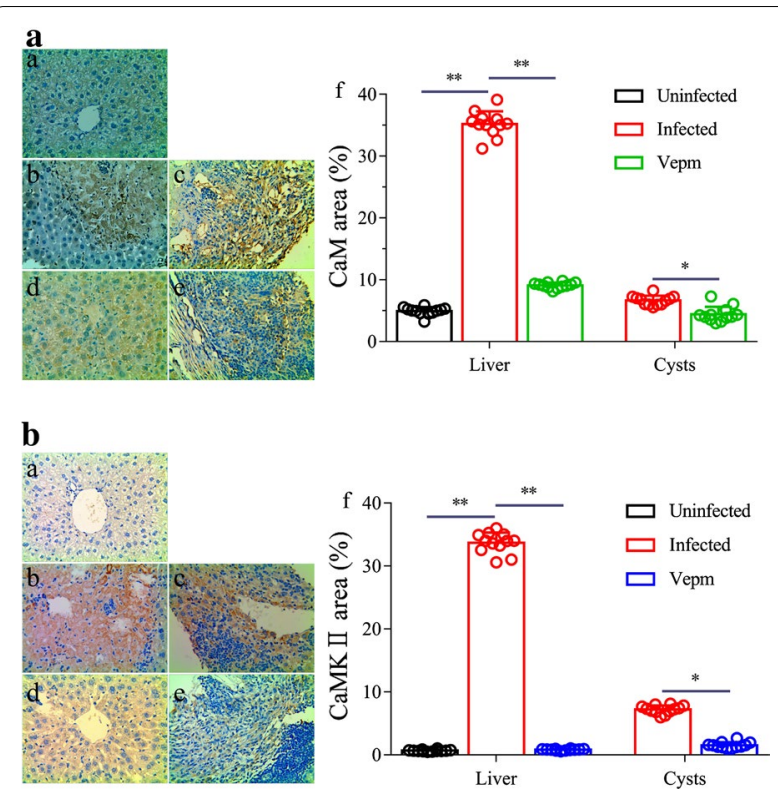

Fig. 5 Analysis of calmodulin (CaM) and $\mathrm{Ca}^{2+} /$ calmodulin-dependent protein kinase II (CaMKII) protein expression in the liver and $E$. multilocularis cysts after treatment with Vepm, as determined by immunohistochemistry-paraffin. The protein expression of CaM (a) and CaMKII (b) in the livers $(a, b, d)$ and E. multilocularis cysts $(c, e)$ of uninfected $(a)$, infected $(b, c)$ and Vepm-treated $(d, e)$ mice $(\times 400$ magnification). $f$ Semiquantitative analysis of $\mathrm{CaM}$ and CaMKIl protein expression

Table 3 Analysis of calmodulin (CaM) and $\mathrm{Ca}^{2+} /$ calmodulindependent protein kinase $\|$ (CaMKII) protein levels in $E$. multilocularis-infected mice after oral administration of Vepm for 4 months by enzyme-linked immunosorbent assay

\begin{tabular}{lllrl}
\hline Index & Sample & $\begin{array}{l}\text { Uninfected } \\
\text { group }\end{array}$ & \multicolumn{1}{l}{$\begin{array}{l}\text { Infected } \\
\text { group }^{\mathrm{a}}\end{array}$} & Vepm group $^{\mathrm{b}}$ \\
\hline CaM $(\mu \mathrm{g} / \mathrm{ml})$ & Serum & $13.81 \pm 1.65$ & $22.25 \pm 5.55^{*}$ & $8.13 \pm 1.26^{*}$ \\
& Liver & $3.42 \pm 0.27$ & $6.06 \pm 1.83^{*}$ & $1.60 \pm 0.68^{*}$ \\
& Cysts & NA & $2.36 \pm 0.87$ & $1.68 \pm 0.10$ \\
CaMKII (ng/ & Serum & $5.88 \pm 0.99$ & $22.87 \pm 4.23^{*}$ & $5.13 \pm 1.74^{*}$ \\
ml) & Liver & $2.00 \pm 0.61$ & $4.25 \pm 1.84^{*}$ & $1.97 \pm 0.56^{*}$ \\
& Cysts & NA & $2.65 \pm 1.24$ & $1.79 \pm 0.36$ \\
\hline
\end{tabular}

\footnotetext{
${ }^{*} P<0.05$

a Infected group vs. the uninfected group

${ }^{b}$ Vepm group vs. the infected group
}

CaMKII mRNA expression in E. granulosus PSC exposed to Vepm in vitro was clearly downregulated (Fig. 6c).

\section{Discussion}

Echinococcus granulosus and Echinococcus multilocularis metacestodes tend to parasitize the liver, and E. multilocularis metacestodes, which exhibit tumor-like growth, become more noticeable and lead to death if untreated [34]. While its intestinal absorption is poor and it is associated with severe side effects [7], ABZ, which exerts a parasitostatic rather than a parasiticidal effect, has long been used to treat human echinococcosis. Hence, new anti-echinococcal targets and therapeutic options should be urgently explored.

The $\mathrm{Ca}^{2+} / \mathrm{CaM}-\mathrm{CaMK}$ pathway is a potential therapeutic target for cancers, and is closely monitored in many cases of parasitosis. However, as it is unclear how $\mathrm{Ca}^{2+}$ / CaM-CaMKII regulates the growth and development of Echinococcus spp., this needs to be explored to identify potential drugs for the treatment of echinococcosis at early stages of the disease.

The results of the present study indicated that the anti-echinococcal effect of Vepm on E. granulosus PSC was time- and dose-dependent, similar to the inhibitory effects of this drug on tumor proliferation. Calcareous corpuscles in PSC can persistently provide abundant calcium sources to promote the development of PSC into cysts [24]. In the present study, rapid disappearance of calcareous corpuscles and a decrease in the calcium content in E. granulosus PSC were induced by exposure to Vepm, indicating that Vepm kills E. granulosus PSC by promoting calcium loss.

$\mathrm{AE}$ is often called "parasitic cancer" due to the distinctive tumor-like growth (metacestode) of E. multilocularis larvae; in $\mathrm{AE}$, approximately $70 \%$ of the metacestodes are found in the right lobe of the patient's liver. The germinal layer cells in E. multilocularis metacestodes have high regenerative capacity and can develop into new multicellular structures, such as PSC, which can further develop into new metacestodes. Therefore, E. multilocularis metacestodes can infiltrate the whole liver of the host [35]. In this study, an infection model was established by in situ surgical intrahepatic implantation to reproduce the natural onset and development of $\mathrm{AE}$ in mice as closely as possible. After E. multilocularis-infected mice were treated with $40 \mathrm{mg} / \mathrm{kg}$ Vepm for 4 months, the weight of E. multilocularis cysts was significantly decreased, suggesting that the growth of the metacestodes was suppressed. This finding is similar to those reported by Cao on the effect of Vepm in mice with CE [26]. Infection with E. multilocularis metacestodes was reported to reduce serum calcium levels in both mice and humans $[25,36]$. Interestingly, our results revealed that the reduction in the calcium content in E. multilocularis-infected mice was significantly reversed after administration of Vepm, and an apparent mild increase was observed in the liver but not in the serum or cysts. The calcium content in E. multilocularis metacestodes was substantially higher than those in the host liver and serum, indicating that the development of $E$. multilocularis PSC into metacestodes 

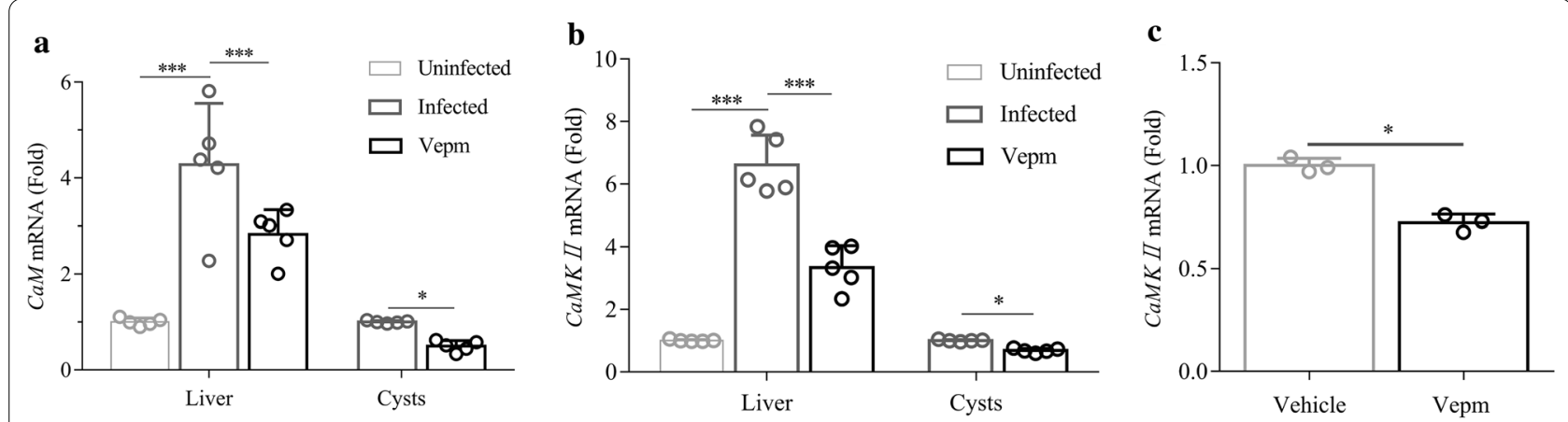

Fig. 6a-c Expression of CaM and CaMKII mRNA in the livers and E. multilocularis cysts of mice after treatment with $40 \mathrm{mg} / \mathrm{kg}$ Vepm for $4 \mathrm{months}$ and in E. granulosus PSC after exposure to Vepm $(20 \mu \mathrm{g} / \mathrm{ml})$ for 4 days, as measured by real-time quantitative polymerase chain reaction. a CaM mRNA expression, b CaMKII mRNA expression, c CaMKII mRNA expression in E. granulosus PSC. For abbreviations, see Figs. 1 and 5

requires continuous absorption of calcium from the host. Furthermore, the results of the SEM-EDS assay showed that treatment with Vepm clearly reduced the calcium content and the number of germinal layer cells. Thus, we speculate that the proliferation of germinal layer cells is regulated by calcium supply in infected mice and can be disrupted by the calcium channel inhibitor Vepm. However, the detailed mechanism by which Vepm suppresses the growth of germinal layer cells by regulating the $\mathrm{Ca}^{2+}$ / CaM-CaMK cascade requires additional investigation. Furthermore, the results of alizarin red staining and ICPMS suggested that E. multilocularis metacestodes cause calcium translocation from mice into the parasite, and that a calcium channel inhibitor (Vepm) reverses calcium loss in E. multilocularis-infected mice. In addition, abundant lymphocytes surrounded the $E$. multilocularis cysts in the liver after treatment with Vepm, which may have been associated with an increase in the calcium content in the livers of $E$. multilocularis-infected mice after treatment with Vepm, probably because a sufficient level of calcium can promote the proliferation and polarization of $\mathrm{T}$ cells [37]. However, the abnormal changes in lymphocyte development caused by calcium loss in Echinococcus-infected hosts requires further investigation.

Our results indicated that an increase in the expression of CaM and CaMKII proteins in mouse serum and liver was caused by $E$. multilocularis metacestode infection; however, overexpression of the CaM and CaMKII proteins was significantly suppressed by Vepm. Furthermore, the expression of CaM and CaMKII mRNA in the mouse liver and in E. multilocularis metacestodes was downregulated after treatment with Vepm. Our results partially support the recent findings of Nawaratna, who showed that $\mathrm{Ca}^{2+} / \mathrm{CaM}-\mathrm{CaMKII}$ is a putative therapeutic target for helminth parasite infection that can provide biochemical and pharmacological information for exploring novel compounds in the future [38]. $\mathrm{Ca}^{2+} /$ CaM-CaMKII controls the completion of the life cycle in Echinococcus, and the calcium channel blocker Vepm has strong inhibitory effects against Echinococcus, including their germinal layer cells, PSC and metacestodes. Therefore, subsequent studies should evaluate the molecular and immune mechanisms of the effects of Vepm on the over-activation of the $\mathrm{Ca}^{2+} / \mathrm{CaM}$-CaMKII pathway in Echinococcus-infected hosts. Furthermore, novel antiechinococcal drug targets and effective treatment strategies associated with $\mathrm{Ca}^{2+} / \mathrm{CaM}-\mathrm{CaMKII}$ should be carefully investigated.

\section{Conclusions}

The results of our study suggested that Vepm has parasiticidal effects on E. granulosus PSC in vitro by promoting calcium loss, and on E. multilocularis metacestodes in vivo by inhibiting calcium translocation from mice to parasites. Furthermore, $\mathrm{Ca}^{2+} / \mathrm{CaM}-\mathrm{CaM}-$ $\mathrm{KII}$ in mice is over-activated by Echinococcus infection, and this effect is alleviated by oral administration of Vepm. Thus, our findings provide new information by identifying $\mathrm{Ca}^{2+} / \mathrm{CaM}-\mathrm{CaMKII}$ as the target of the anti-Echinococcus effects of Vepm. Investigation of the functions of $\mathrm{Ca}^{2+} / \mathrm{CaM}-\mathrm{CaMKII}$ in the growth and development of Echinococcus and the chronic toxicity of Vepm is currently in progress in our laboratory.

\section{Abbreviations}

ABZ: Albendazole; ABZ-SO: Albendazole sulfoxide; AE: Alveolar echinococcosis; CaM: Calmodulin; CaMKII: Ca ${ }^{2+} /$ calmodulin-dependent protein kinase II; CE: Cystic echinococcosis; DMSO: Dimethylsulfoxide; ELISA: Enzyme-linked immunosorbent assay; ICP-MS: Inductively coupled plasma mass spectrometry; IHC-P: Immunohistochemistry-paraffin; PBS: Phosphate buffered saline; PSC: Protoscoleces; RT-qPCR: Real-time quantitative polymerase chain reaction; SEM-EDS: Scanning electron microscopy-energy dispersive X-ray spectrometry; Vepm: Verapamil. 


\section{Acknowledgements}

The authors would like to thank Dr. H. B. Zhang, B. Jiang and L. L. Huo (National Institute of Parasitic Diseases, Chinese Center for Disease Control and Prevention, Key Laboratory of Parasite and Vector Biology of the Chinese Ministry of Health, National Center for International Research on Tropical Diseases, WHO Collaborating Centre for Tropical Diseases, China) for their technical assistance.

\section{Authors' contributions}

TJ, TZ and HJG conceived and designed the experiments; HJG and YPL performed the experiments; HJG, TZ, WH, XMM, YJS, JPC analyzed the data and contributed reagents and materials; XDS and HSP participated in developing the animal model; HJG and TZ wrote the paper. All the authors read and approved the final manuscript.

\section{Funding}

This study was financially supported by the Foundation of National Science and Technology Major Program (no. 2018ZX10713001-004), the National Natural Science Foundation of China (no. 81171632 and 81201315), the Fundamental Research Funds for the Central Universities (no. Izujbky-2014-m02), the Foundation of Shanghai Municipal Health Commission (no. 201940302) and the Non-profit Central Research Institute Fund of Chinese Academy of Medical Sciences (no. 2019PT320004). The funders had no role in the study design, data collection, data analysis, data interpretation, or the writing of this report.

\section{Availability of data and materials}

The datasets supporting the conclusions of this article are included within the article.

\section{Ethics approval and consent to participate}

This study was conducted in accordance with the Chinese Laboratory Animal Administration Act, and the study protocol was approved by the Experimental Animal Ethics Committee of the School of Basic Medical Sciences, Lanzhou University (permit no. 2014-12-003).

\section{Consent for publication}

Not applicable.

\section{Competing interests}

The authors declare that they have no competing interests.

\section{Author details}

${ }^{1}$ School of Basic Medical Sciences, Lanzhou University, Lanzhou 730000, Gansu Province, People's Republic of China. ${ }^{2}$ National Institute of Parasitic Diseases, Chinese Center for Disease Control and Prevention, WHO Collaborating Center for Tropical Diseases, National Center for International Research on Tropical Diseases, Key Laboratory of Parasite and Vector Biology of the Chinese Ministry of Health, Shanghai 200025, People's Republic of China. ${ }^{3}$ Ganzr Tibetan Autonomous Prefecture Center for Disease Control and Prevention, Kangding 626000, Sichuan Province, People's Republic of China. ${ }^{4}$ National Health Commission Key Laboratory of Echinococcosis Prevention and Control, Tibet Autonomous Region Center for Disease Control and Prevention, Lhasa 850000, Tibet Autonomous Region, People's Republic of China.

Received: 12 November 2020 Accepted: 29 January 2021

Published online: 15 February 2021

\section{References}

1. Wang H, Li J, Guo B, Zhao L, Zhang Z, McManus DP, et al. In vitro culture of Echinococcus multilocularis producing protoscoleces and mouse infection with the cultured vesicles. Parasites Vectors. 2016;9:411.

2. Romig T, Deplazes P, Jenkins D, Giraudoux P, Massolo A, Craig PS, et al. Ecology and life cycle patterns of Echinococcus species. Adv Parasitol. 2017;95:213-314.

3. Li ZD, Mo XJ, Yan S, Wang D, Xu B, Guo J, et al. Multiplex cytokine and antibody profile in cystic echinococcosis patients during a three-year follow-up in reference to the cyst stages. Parasites Vectors. 2020;13:133.

4. Kern P, Menezes da Silva A, Akhan O, Mullhaupt B, Vizcaychipi KA, Budke $C$, et al. The echinococcoses: diagnosis, clinical management and burden of disease. Adv Parasitol. 2017;96:259-369.
5. Horton J. Albendazole: a review of anthelmintic efficacy and safety in humans. Parasitology. 2000;121:S113-32.

6. Fabbri J, Pensel PE, Albani CM, Arce VB, Martire DO, Elissondo MC. Drug repurposing for the treatment of alveolar echinococcosis: in vitro and in vivo effects of silica nanoparticles modified with dichlorophen. Parasitology. 2019;146:1620-30.

7. Yuan M, Luo Y, Xin Q, Gao H, Zhang G, Jing T. Efficacy of osthole for Echinococcus granulosus in vitro and Echinococcus multilocularis in vivo. Vet Parasitol. 2016;226:38-43.

8. Stamatakos M, Sargedi C, Stefanaki C, Safioleas C, Matthaiopoulou I, Safioleas M. Anthelminthic treatment: an adjuvant therapeutic strategy against Echinococcus granulosus. Parasitol Int. 2009;58:115-20.

9. Abdel-Baki AA, Almalki E, Mansour L, Al-Quarishy S. In vitro scolicidal effects of Salvadora persica root extract against protoscolices of Echinococcus granulosus. Korean J Parasitol. 2016;54:61-6.

10. Nicolao MC, Elissondo MC, Denegri GM, Goya AB, Cumino AC. In vitro and in vivo effects of tamoxifen against larval stage Echinococcus granulosus. Antimicrob Agents Chemother. 2014;58:5146-54.

11. Colebrook AL, Jenkins DJ, Jones MK, Tatarczuch L, Lightowlers MW. Effect of cyclosporin A on the survival and ultrastructure of Echinococcus granulosus protoscoleces in vitro. Parasitology. 2004;129:497-504.

12. Reuter S, Merkle M, Brehm K, Kern P, Manfras B. Effect of amphotericin B on larval growth of Echinococcus multilocularis. Antimicrob Agents Chemother. 2003;47:620-5.

13. Iamshanova O, Fiorio Pla A, Prevarskaya N. Molecular mechanisms of tumour invasion: regulation by calcium signals. J Physiol. 2017:595:3063-75

14. Billker O, Lourido S, Sibley LD. Calcium-dependent signaling and kinases in apicomplexan parasites. Cell Host Microbe. 2009;56:612-22.

15. Cui C, Merritt R, Fu L, Pan Z. Targeting calcium signaling in cancer therapy. Acta Pharm Sin B. 2017:71:3-17.

16. Hu Y, Liu P, Kang L, Li J, Li R, Liu T. Mechanism of Marsdenia tenacissima extract promoting apoptosis of lung cancer by regulating $\mathrm{Ca}(2+) / \mathrm{CaM}$ / CaMK signaling. J Ethnopharmacol. 2020;251:1125-35.

17. Thomas CM, Timson DJ. Calmodulins from Schistosoma mansoni: biochemical analysis and interaction with IQ-motifs from voltage-gated calcium channels. Cell Calcium. 2018;74:1-13.

18. Zou X, Jin Y, Liu P, Wu Q, Liu J, Lin J. RNAi silencing of calcium-regulated heat-stable protein of $24 \mathrm{kDa}$ in Schistosoma japonicum affects parasite growth. Parasitol Res. 2010;108(3):567-72.

19. Cho PY, Yoo WG, Kim TI, Ahn SK, Cho SH, Kim TS, et al. Molecular characterization of voltage-gated calcium channel beta-subunits of Clonorchis sinensis. Parasitol Res. 2014;113(1):121-9.

20. McCammick EM, McVeigh P, McCusker P, Timson DJ, Morphew RM, Brophy PM, et al. Calmodulin disruption impacts growth and motility in juvenile liver fluke. Parasites Vectors. 2016;9:46.

21. Zhao L, Zhao Y, Schwarz B, Mysliwietz J, Hartig R, Camaj P, et al. Verapamil inhibits tumor progression of chemotherapy-resistant pancreatic cancer side population cells. Int J Oncol. 2016;49(1):99-110.

22. Harun MSR, Marsh V, Elsaied NA, Webb KF, Elsheikha HM. Effects of Toxoplasma gondii infection on the function and integrity of human cerebrovascular endothelial cells and the influence of verapamil treatment in vitro. Brain Res. 2020;1746:147002.

23. Zhang $Y T$, Hu HH, Chen W, Shi S, Weng W. Influence of wenxin granule on atrial myocytes calcium-handling CaV1.2-CaM-CaMKII signal pathway of atrial brillation rat. China J Trad Chin Med Pharm. 2017;32(5):2246-9.

24. Rodrigues JJS, Ferreira HB, Farias SE, Zaha A. A protein with a novel calcium-binding domain associated with calcareous corpuscles in Echinococcus granulosus. Biochem Biophys Res Commun. 1997;237(2):451-6.

25. Desser SS. Calcium accumulation in larval Echinococcus multilocularis. Can J Zool. 1963;41(6):1055-9.

26. Cao D, Bai H, Zhao H. Effects of verapamil hydrochloride on the ultrastructures of secondary cysts of Echinococcus granulosus in mice. J Parasit Biol. 2010;5(6):448-9 (in Chinese).

27. Cao D, Shi D, Bao G. Observation on verapamil and albendazole against Echinococcus granulosus protoscolex in vitro. Endemic Dis Bull. 2004;19(1):23-4 (in Chinese).

28. Naguleswaran A, Spicher M, Vonlaufen N, Ortega-Mora LM, Torgerson P, Gottstein B, et al. In vitro metacestodicidal activities of genistein and other isoflavones against Echinococcus multilocularis and Echinococcus granulosus. Antimicrob Agents Chemother. 2006;50(11):3770-8. 
29. Orct T, Jurasovic J, Micek V, Karaica D, Sabolic I. Macro- and microelements in the rat liver, kidneys, and brain tissues; sex differences and effect of blood removal by perfusion in vivo. J Trace Elem Med Biol. 2017;40:104-11.

30. Jung M, Jang HB, Lee SE, Park JH, Hwang YS. In vitro micro-mineralized tissue formation by the combinatory condition of adipose-derived stem cells, macroporous PLGA microspheres and a bioreactor. Macromol Res. 2013;22(1):47-57.

31. Mori F, Tanji K, Wakabayashi K. Widespread calcium deposits, as detected using the alizarin red $\mathrm{S}$ technique, in the nervous system of rats treated with dimethyl mercury. Neuropathology. 2000;20(3):210-5.

32. Xu B, Xing R, Huang Z, Yin S, Li X, Zhang L, et al. Excessive mechanical stress induces chondrocyte apoptosis through TRPV4 in an anterior cruciate ligament-transected rat osteoarthritis model. Life Sci. 2019;228:158-66.

33. Yang WR, Li BB, Hu Y, Zhang L, Wang XZ. Oxidative stress mediates heatinduced changes of tight junction proteins in porcine sertoli cells via inhibiting CaMKKß-AMPK pathway. Theriogenology. 2020;142:104-13.

34. Maria AC, Celina EM. Efficacy of albendazole in combination with thymol against Echinococcus multilocularis protoscoleces and metacestodes. Acta Trop. 2014;140:61-7.
35. Diaz A, Casaravilla C, Irigoin F, Lin G, Previato JO, Ferreira F. Understanding the laminated layer of larval Echinococcus. I. Structure. Trends Parasitol. 2011;27(5):204-13.

36. Wang Y, Wang S, Pu Y, Zhu J, Zhao W. Observation of trace elements in serum of patients with hepatic echinococcosis. J Ningxia Med Univ. 2011;33(8):764-5 (in Chinese).

37. Vaeth M, Maus M, Klein-Hessling S, Freinkman E, Yang J, Eckstein M, et al. Store-operated $\mathrm{Ca}(2+)$ entry controls clonal expansion of T cells through metabolic reprogramming. Immunity. 2017;47(4):664-79.

38. Nawaratna SSK, You H, Jones MK, McManus DP, Gobert GN. Calcium and $\mathrm{Ca}(2+) / c a l m o d u l i n-d e p e n d e n t$ kinase II as targets for helminth parasite control. Biochem Soc Trans. 2018;46(6):1743-51.

\section{Publisher's Note}

Springer Nature remains neutral with regard to jurisdictional claims in published maps and institutional affiliations.
Ready to submit your research? Choose BMC and benefit from:

- fast, convenient online submission

- thorough peer review by experienced researchers in your field

- rapid publication on acceptance

- support for research data, including large and complex data types

- gold Open Access which fosters wider collaboration and increased citations

- maximum visibility for your research: over $100 \mathrm{M}$ website views per year

At BMC, research is always in progress.

Learn more biomedcentral.com/submissions 